\title{
Fe-substituted molecular sieves as catalysts in liquid phase pinacol rearrangement
}

\author{
Michelle Hsien ${ }^{a}$, Horng-Tay Sheu ${ }^{a}$, Tao Lee ${ }^{a}$, Soofin Cheng ${ }^{a}{ }^{*}$, Jyh-Fu Lee $^{b}$ \\ ${ }^{a}$ Department of Chemistry, National Taiwan University, Taipei 106, Taiwan \\ ${ }^{\mathrm{b}}$ Research Division, Synchrotron Radiation Research Center, Hsinchu 300, Taiwan
}

Accepted 8 August 2001

\begin{abstract}
Pinacol-type rearrangement reactions in toluene were catalyzed by iron-substituted molecular sieves of different porous structures, including $\mathrm{AlPO}_{4}-5, \mathrm{ZSM}-5$ of micropores and MCM-41 of mesopores. Iron(III)-substituted in the framework of the molecular sieves was found to be the active center for pinacol rearrangement reaction. The catalytic activity was found to have no correlation with the acidity. Ten vicinal diol reactants with various alkyl or aryl substitution were examined. The results showed that $\mathrm{AlPO}_{4}-5$ molecular sieve containing 0.5-2\% Fe was most active in catalyzing the pinacol rearrangement of 2,3-dimethyl-2,3-butanediol. On the other hand, Fe-substituted MCM-41 with relatively large pores was most active in catalyzing the rearrangement of large molecules such as 2,3-pinanediol and 2,3-diphenyl-1,2-ethanediol. All these molecular sieves were not catalytically active in the rearrangement of the vicinal diol compounds of high polarity. This was attributed to the fact that polar molecules would cover the catalyst surfaces and deactivate the catalysts. The migrating preference of the substitution groups was dependent on the catalysts and was different from that observed on acid-catalyzed reactions. (c) 2002 Elsevier Science B.V. All rights reserved.
\end{abstract}

Keywords: Pinacol rearrangement; Iron; Molecular sieve; Catalyst; Substitution; Pore size

\section{Introduction}

The substitution of hetero-elements into the framework of molecular sieves was usually reported to create acidic sites, while the incorporation of transition metal elements, such as $\mathrm{Ti}, \mathrm{V}, \mathrm{Cr}, \mathrm{Mn}, \mathrm{Fe}$ and $\mathrm{Co}$, endows sites for redox reactions [1,2]. Industrially, pinacolone is prepared through pinacol rearrangement in large-scale processes using strong acids such as, $\mathrm{H}_{2} \mathrm{SO}_{4}, \mathrm{H}_{3} \mathrm{PO}_{4}$ or $\mathrm{AlCl}_{3}$ as catalysts [3,4]. The reaction will be much cleaner and more environmentally

\footnotetext{
* Corresponding author. Tel.: +886-2-23638017; fax: +886-2-23636359.

E-mail address: chem1031@ccms.ntu.edu.tw (S. Cheng).
}

friendly if the corrosive acids can be replaced by solid catalysts. Some efforts have been devoted to this objective in the past few years. The catalysts examined include LaHY, CaHY and HZSM-5 zeolites [5], SAPO molecular sieves [6] and heteropoly acids [7]. In all these reports, the catalytic activities were attributed to the acidities of the catalysts. Our previous study found that pinacol rearrangement proceeded at relatively mild temperature in solution over metal-substituted aluminophosphate molecular sieves [8]. Moreover, among the first row transition metal elements substituted in AFI crystal structure, $\mathrm{Fe}^{3+}$, $\mathrm{Cu}^{2+}$ and $\mathrm{Ni}^{2+}$ in order are the three which gave the highest pinacol conversions and pinacolone selectivities. In contrast, under the same reaction condition, 
HY and HZSM-5 zeolites of relatively stronger acidity in comparison to MAPO molecular sieves, have very low catalytic activities. These results were explained by that the acidity was not the main factor in catalyzing the pinacol rearrangement reaction in our reaction condition. Instead, the redox of the metal center was proposed to involve in the catalytic reaction. In the present study, the catalytic behavior of Fe-substituted molecular sieves is extended to the rearrangement of various alkyl- and phenyl-substituted vicinal diols. Additionally, the catalytic behavior of three different Fe-substituted molecular sieves, saying $\mathrm{AlPO}_{4}-5, \mathrm{ZSM}-5$ and MCM-41, is compared in order to understand the effect of pore size and zeolitic structure on the rearrangement reaction. The pore diameters of these three molecular sieves were ca. $7.5,5.5$ and $26 \AA$, respectively.

\section{Experimental}

\subsection{Catalyst preparation}

The Fe-substituted molecular sieves were prepared by hydrothermal methods. $\mathrm{Fe}\left(\mathrm{NO}_{3}\right)_{3} \cdot 9 \mathrm{H}_{2} \mathrm{O}(99 \%$, Acros) was the iron source. Triethylamine (TEA, Janssen) was used as template for the synthesis of FeAPO-5, tetrapropylammonium $\left(\mathrm{TPA}^{+}\right)$bromide (Jessen) for FeZSM-5, and cetyltrimethylammonium $\left(\mathrm{CTMA}^{+}\right)$bromide (Acros) for FeMCM-41. The gel mixtures with the molar compositions of 1.05 TEA:(0.01-0.08) $\mathrm{Fe}_{2} \mathrm{O}_{3}: \mathrm{Al}_{2} \mathrm{O}_{3}: \mathrm{P}_{2} \mathrm{O}_{5}: 40 \quad \mathrm{H}_{2} \mathrm{O}$ were crystallized at $200^{\circ} \mathrm{C}$ for $48 \mathrm{~h}$ to synthesize FeAPO-5. Sodium silicate (Aldrich) was used as the silicon source for the synthesis of ZSM-5 and MCM-41. The molar ratio of the final gel composition is $\mathrm{SiO}_{2}:(0.05-0.05) \mathrm{Fe}_{2} \mathrm{O}_{3}: 0.48 \mathrm{CTMA}^{+}: 0.39$ $\mathrm{Na}_{2} \mathrm{O}$ : $(50-110) \mathrm{H}_{2} \mathrm{O}$ for FeMCM-41 and that for FeZSM-5 is $\mathrm{SiO}_{2}:(0.05) \mathrm{Fe}_{2} \mathrm{O}_{3}: 0.21 \mathrm{TPA}^{+}: 0.39$ $\mathrm{Na}_{2} \mathrm{O}$ :(35-100) $\mathrm{H}_{2} \mathrm{O}$ for FeZSM-5. A sample termed $1 \%$ AlZSM-5 was also prepared by using $\mathrm{Al}_{2}\left(\mathrm{SO}_{4}\right)_{3}$ as the $\mathrm{Al}$ source and the $\mathrm{Al} / \mathrm{Si}$ molar ratio in the synthesis gel was $1 \%$. The gel mixture was stirred overnight at room temperature and then transferred to polypropylene bottles and statically heated under autogeneous pressure at $100^{\circ} \mathrm{C}$ for 7 days for MCM-41 or autoclaved with Teflon liner and heated at $200{ }^{\circ} \mathrm{C}$ for 1 day for ZSM-5. The final solid material obtained was washed with plenty of water, dried at $110^{\circ} \mathrm{C}$ for $12 \mathrm{~h}$ and calcined (heating rate $1{ }^{\circ} \mathrm{C} / \mathrm{min}$ ) at $560{ }^{\circ} \mathrm{C}$ for $6 \mathrm{~h}$.

\subsection{Characterization}

Powder XRD patterns were obtained with a Scintag X1 automated powder diffractometer using $\mathrm{Cu} \mathrm{K} \alpha$ radiation. The refinement of lattice parameters was carried out using step scan with $0.01^{\circ}$ and $3 \mathrm{~s}$ per step data collection, followed by analysis with software of peak finder program and lattice refinement function. The BET surface area and pore structures of the samples were analyzed by nitrogen physical adsorption at liquid $\mathrm{N}_{2}$ temperature using a Micromeritics ASAP 2100 system. Prior to the experiments, samples were outgassed at $250{ }^{\circ} \mathrm{C}$ for about $4-6 \mathrm{~h}$ under vacuum $\left(10^{-3}\right.$ Torr $)$. The elemental contents in bulk were determined by ICP-AES (Jarrell-Ash, Model IC $\mathrm{AP} 9000$ ) on the $\mathrm{HF}$ (or $\mathrm{HCl}$ for $\mathrm{AlPO}_{4}-5$ series) dissolved samples. The temperature-programmed desorption (TPD) experiments were carried out on a Du Pont 951 TGA analyzer. The Fe K-edge X-ray absorption spectra were obtained in the transmission mode at the Synchrotron Radiation Research Center, Hsinchu, Taiwan. The ion chambers which were used for measuring the incident and transmitted photon intensities were filled with a mixture of nitrogen and helium, and argon and helium gases, respectively. The photon energies were calibrated using the known absorption edge of Fe foil.

\subsection{Catalytic studies}

Pinacol rearrangement reaction was carried out in a three-necked round-bottom flask fitted with a thermometer and a reflux condenser. The 10 vicinal diol compounds with different alkyl or aryl substitution were reagent grade and purchased from Acros. Table 1 presents the names, chemical formulae and dielectric constants of these compounds. A solution of $0.1 \mathrm{~g}$ diol reactant and $5 \mathrm{~g}$ toluene solvent was heated with stirring at $110^{\circ} \mathrm{C}$. Then, $0.1 \mathrm{~g}$ catalyst powder which was pre-dried at $200^{\circ} \mathrm{C}$ was added into the flask. After $6 \mathrm{~h}$ reaction, the liquid products were separated with a RTX-1 capillary column and analyzed with a FID detector in a Chrompack CP9000 GC. A known quantity of 1,2,4-trimethylbenzene (or THF in the reaction 
Table 1

The name, chemical formula and dielectric constants of vicinal diol reactants:

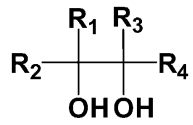

\begin{tabular}{|c|c|c|c|c|c|c|}
\hline Compound no. & Name & $\mathrm{R}_{1}$ & $\mathrm{R}_{2}$ & $\mathrm{R}_{3}$ & $\mathrm{R}_{4}$ & $\varepsilon^{\mathrm{a}}$ \\
\hline 1 & Ethylene glycol & $\mathrm{H}$ & $\mathrm{H}$ & $\mathrm{H}$ & $\mathrm{H}$ & 41.4 \\
\hline 2 & 1,2-Propanediol & $\mathrm{CH}_{3}$ & $\mathrm{H}$ & $\mathrm{H}$ & $\mathrm{H}$ & 27.5 \\
\hline 3 & 1,2-Butanediol & $\mathrm{C}_{2} \mathrm{H}_{5}$ & $\mathrm{H}$ & $\mathrm{H}$ & $\mathrm{H}$ & 22.4 \\
\hline 4 & 2,3-Butanediol & $\mathrm{CH}_{3}$ & $\mathrm{H}$ & $\mathrm{CH}_{3}$ & $\mathrm{H}$ & - \\
\hline 5 & Pinacol (2,3-dimethyl-2,3-butanediol) & $\mathrm{CH}_{3}$ & $\mathrm{CH}_{3}$ & $\mathrm{CH}_{3}$ & $\mathrm{CH}_{3}$ & - \\
\hline 6 & 1,2-Hexanediol & $\mathrm{C}_{4} \mathrm{H}_{9}$ & $\mathrm{H}$ & $\mathrm{H}$ & $\mathrm{H}$ & - \\
\hline 7 & 1,2-Octanediol & $\mathrm{C}_{6} \mathrm{H}_{13}$ & $\mathrm{H}$ & $\mathrm{H}$ & $\mathrm{H}$ & - \\
\hline 8 & 1-Phenyl-1,2-ethanediol & $\mathrm{C}_{6} \mathrm{H}_{5}$ & $\mathrm{H}$ & $\mathrm{H}$ & $\mathrm{H}$ & - \\
\hline 9 & 2,3-Pinanediol & $\mathrm{CH}_{3}$ & $\mathrm{CR}_{5} \mathrm{R}_{6}$ & $\mathrm{H}$ & $\mathrm{CH}_{2} \mathrm{R}_{7}$ & - \\
\hline 10 & 1,2-Diphenyl-1,2-ethanediol & $\mathrm{C}_{6} \mathrm{H}_{5}$ & $\mathrm{H}$ & $\mathrm{C}_{6} \mathrm{H}_{5}$ & $\mathrm{H}$ & - \\
\hline
\end{tabular}

${ }^{a}$ Dielectric constant from CRC handbook.

of 1-phenyl-1,2-ethanediol) was added into the liquid products and served as the internal standard for quantitative analysis. A HP5980-5973 GC-MAS was used for identification of complex products.

\section{Results and discussion}

\subsection{Catalyst characterization}

The XRD patterns of Fe-incorporated molecular sieves show that the crystalline structures were well retained. In the case of $\mathrm{Fe}$-substituted $\mathrm{AlPO}_{4}-5$, the unit cell volume was found to increase with Fe-loading (Table 2). The expansion of the unit cell volume is in line with the theoretical expansion based on the difference in the ionic radii of $\mathrm{Al}^{3+}(0.53 \AA)$ and $\mathrm{Fe}^{3+}$ $(0.77 \AA)$ [9] as well as the amount of $\mathrm{Al}^{3+}$ on framework substituted by $\mathrm{Fe}^{3+}$. On the other hand, the data for ZSM-5 in Table 3 shows greater expansion in unit cell volume. The change is markedly high for $2 \%$ Fe-loaded sample. The unusual expansion in unit cell volume is attributed to the relatively poor crystallinity of Fe-substituted ZSM-5, which causes greater deviation in the lattice refinement. For MCM-41, Fig. 1 shows that the long-range order of the hexagonal
Table 2

Lattice parameters of FeAPO-5 with different Fe-loadings ${ }^{\mathrm{a}}$

\begin{tabular}{llll}
\hline Catalyst & $a, b(\AA)$ & $c(\AA)$ & $\begin{array}{l}\text { Unit cell } \\
\text { volume }\left(\AA^{3}\right)\end{array}$ \\
\hline AlPO $_{4}-5$ & 13.633 & 8.5014 & 1368.3 \\
$0.5 \%$ FeAPO-5 & 13.638 & 8.5025 & 1369.6 \\
$1 \%$ FeAPO-5 & 13.648 & 8.5062 & 1372.1 \\
$2 \%$ FeAPO-5 & 13.670 & 8.5106 & 1377.3 \\
$3 \%$ FeAPO-5 & 13.661 & 8.5258 & 1377.9 \\
$4 \%$ FeAPO-5 & 13.662 & 8.5283 & 1378.5 \\
\hline
\end{tabular}

${ }^{a}$ Uncalcined samples in hexagonal crystal system.

arrangement was disturbed with Fe-loading. The $\mathrm{X}$-ray diffraction peaks broadened with the increase in Fe-content. The relatively sharp peaks for sample $4 \%$ FeMCM-41 of high Fe-loading is probably due to that

Table 3

Lattice parameters of FeZSM-5 with different Fe-loadings ${ }^{\mathrm{a}}$

\begin{tabular}{lcccl}
\hline Catalyst & $a(\AA)$ & $b(\AA)$ & $c(\AA)$ & $\begin{array}{l}\text { Unit cell } \\
\text { volume }\left(\AA^{3}\right)\end{array}$ \\
\hline ZSM-5 & 19.949 & 19.949 & 13.370 & 5320.8 \\
$0.5 \%$ FeZSM-5 & 19.947 & 19.947 & 13.371 & 5320.1 \\
1\% FeZSM-5 & 19.956 & 19.956 & 13.382 & 5329.3 \\
2\% FeZSM-5 & 20.060 & 20.060 & 13.453 & 5413.5 \\
\hline
\end{tabular}

\footnotetext{
${ }^{\text {a }}$ Uncalcined samples in tetragonal crystal system.
} 


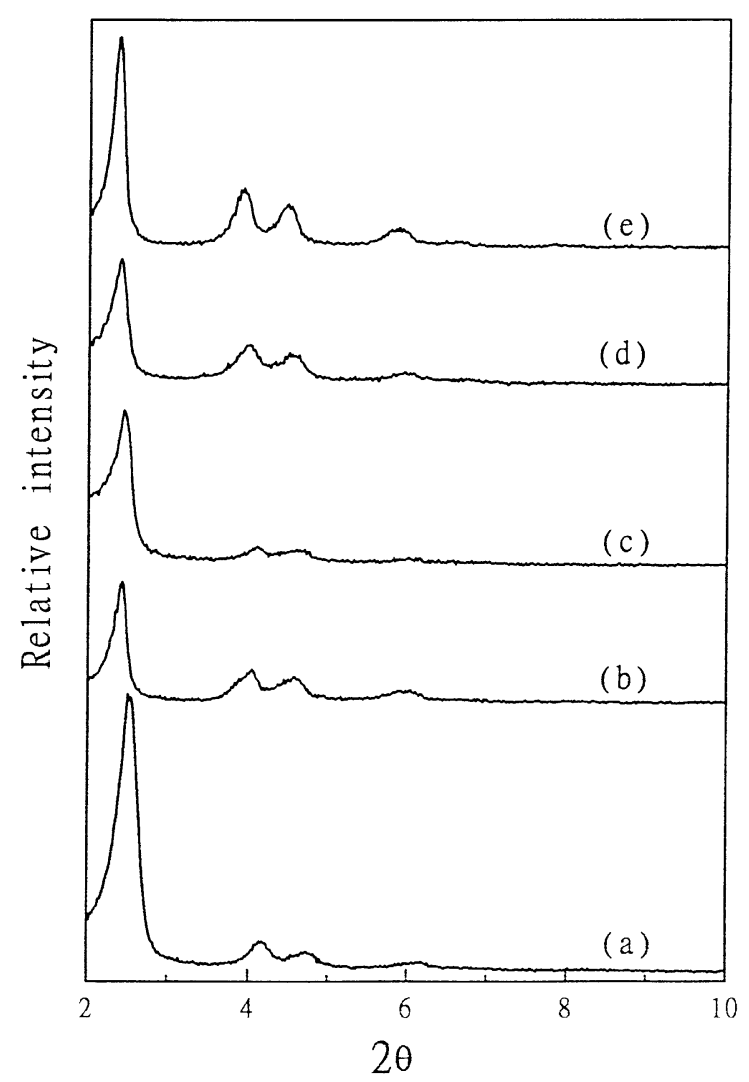

Fig. 1. XRD patterns of MCM-41 with different Fe-loadings: (a) $0 \% \mathrm{Fe}$, (b) $1 \% \mathrm{Fe}$, (c) $2 \% \mathrm{Fe}$, (d) $3 \% \mathrm{Fe}$, and (e) $4 \% \mathrm{Fe}$.

a portion of $\mathrm{Fe}^{3+}$ was present in the extra-framework instead of being incorporated in the framework.

The Fe-loading in the synthetic gels was varied from 0.5 to $4 \%$ based on $\mathrm{Fe} / \mathrm{Si}$ or $\mathrm{Fe} /(\mathrm{Al}+\mathrm{P})$ molar ratio. Tables 4 and 5 show that the Fe-contents in FeAPO-5 and FeMCM-41 analyzed by ICP-AES are close to those added in the synthetic gels. It is noticeable that the $\mathrm{Al} / \mathrm{P}$ ratios in FeAPO-5 are less than 1. Moreover, the $\mathrm{Al} / \mathrm{P}$ ratio decreases as the $\mathrm{Fe}-$ content increases. These results imply that $\mathrm{Fe}^{3+}$ ions are substituting the $\mathrm{Al}^{3+}$ positions in the framework. The exceptional high $\mathrm{Al} / \mathrm{P}$ ratio observed on sample $4 \% \mathrm{FeAPO}-5$ indicates that a portion of $\mathrm{Fe}$ or $\mathrm{Al}$ may not be incorporated in the framework. On the other hand, the Al- and Fe-contents in ZSM-5 were much higher than that in the synthetic gels (Table 6). This is attributed to the fact that a portion of the Si probably remained in the solution as silicate ions because the final $\mathrm{pH}$ value of the synthetic gels of ZSM-5 was around 11 .

The BET surface areas of the Fe-incorporated molecular sieves are given in Tables 4-6. Most of the Fe-containing samples still retained high surface area as the pristine molecular sieves. The apparent decrease in surface area was only found on FeZSM-5. The low surface area of FeZSM-5 samples is due to their relatively low crystallinity, that also accounts for the great deviation in unit cell volume determination.

In order to understand the oxidation state and coordination environment of $\mathrm{Fe}$ in the molecular sieves, $\mathrm{X}$-ray absorption spectra were taken. Fig. 2 shows the X-ray absorption near-edge spectra (XANES) of the Fe-incorporated molecular sieves before and after heating at $200{ }^{\circ} \mathrm{C}$ in $\mathrm{N}_{2}$, in comparison to those of $\mathrm{FeO}$ and $\mathrm{Fe}_{2} \mathrm{O}_{3}$ standards. The edge-energies determined from the inflections of the absorption edges were $7118.6 \mathrm{eV}$ for $\mathrm{FeO}$ and $7124.0 \mathrm{eV}$ for $\mathrm{Fe}_{2} \mathrm{O}_{3}$. That of $1 \%$ FeAPO-5 was $7125.2 \mathrm{eV}$, indicating that $\mathrm{Fe}$ was in the +3 oxidation state. After heating $1 \%$ FeAPO-5 at $200{ }^{\circ} \mathrm{C}$, the absorption peak became broader and the edge-energy shifted slightly

Table 4

The composition and surface area of calcined FeAPO-5

\begin{tabular}{|c|c|c|c|c|c|c|c|}
\hline \multirow[t]{3}{*}{ Catalyst } & \multicolumn{6}{|c|}{ Molar ratio } & \multirow[t]{3}{*}{ BET surface area $\left(\mathrm{m}^{2} / \mathrm{g}\right)$} \\
\hline & \multicolumn{3}{|l|}{ Gel } & \multicolumn{3}{|c|}{ Product $^{\mathrm{a}}$} & \\
\hline & $\mathrm{Fe}$ & $\mathrm{P}$ & $\mathrm{Al}$ & $\mathrm{Fe}$ & $\mathrm{P}$ & $\mathrm{Al}$ & \\
\hline $\mathrm{AlPO}_{4}-5$ & 0 & 1 & 1 & 1 & 1 & 0.98 & 290 \\
\hline $0.5 \% \mathrm{FeAPO}-5$ & 0.01 & 1 & 1 & 0.011 & 1 & 0.96 & 272 \\
\hline $1 \%$ FeAPO-5 & 0.02 & 1 & 1 & 0.022 & 1 & 0.93 & 273 \\
\hline $2 \% \mathrm{FeAPO}-5$ & 0.04 & 1 & 1 & 0.039 & 1 & 0.92 & 270 \\
\hline $3 \%$ FeAPO-5 & 0.06 & 1 & 1 & 0.059 & 1 & 0.93 & 272 \\
\hline $4 \%$ FeAPO-5 & 0.08 & 1 & 1 & 0.089 & 1 & 0.96 & 284 \\
\hline
\end{tabular}

\footnotetext{
${ }^{a}$ From ICP-AES analysis.
} 
Table 5

The composition and surface area of calcined FeMCM-41

\begin{tabular}{|c|c|c|c|c|c|c|c|}
\hline \multirow[t]{3}{*}{ Catalyst } & \multicolumn{6}{|c|}{ Molar ratio } & \multirow[t]{3}{*}{ BET surface area $\left(\mathrm{m}^{2} / \mathrm{g}\right)$} \\
\hline & \multicolumn{3}{|l|}{ Gel } & \multicolumn{3}{|c|}{ Product $^{\mathrm{a}}$} & \\
\hline & $\mathrm{Fe}$ & $\mathrm{Si}$ & $\mathrm{Fe} / \mathrm{Si}$ & $\mathrm{Fe}$ & $\mathrm{Si}$ & $\mathrm{Fe} / \mathrm{Si}$ & \\
\hline MCM-41 & 0 & 1 & 0 & 0 & 1 & 0 & 1008 \\
\hline $1 \%$ FeMCM-41 & 0.01 & 1 & 0.01 & 0.011 & 1 & 0.011 & 974 \\
\hline $2 \%$ FeMCM-41 & 0.02 & 1 & 0.02 & 0.023 & 1 & 0.023 & 1008 \\
\hline 3\% FeMCM-41 & - & - & - & - & - & - & 1074 \\
\hline 4\% FeMCM-41 & - & - & - & - & - & - & 954 \\
\hline
\end{tabular}

${ }^{\text {a }}$ Calcined samples.

to $7123.5 \mathrm{eV}$. Moreover, an apparent increase in the intensity of the pre-edge peak was seen. Judging from the edge energy, iron in the dried $1 \%$ FeAPO-5 should retain in the +3 oxidation state, but its coordination environment was changed. The pre-edge peak is assigned to the $1 \mathrm{~s} \rightarrow 3 \mathrm{~d}$ electron transition. In octahedral coordination environment, this transition is $\mathrm{La}$ Porte forbidden. However, in a non-central symmetric or tetrahedral coordination, this transition is allowed. The coordination environment of $\mathrm{Fe}^{3+}$ which changes from octahedral to tetrahedral elucidates the increase in intensity of the pre-edge peak after heating of FeAPO-5. The $\mathrm{Fe}^{3+}$ which substitutes $\mathrm{Al}^{3+}$ in the $\mathrm{AlPO}_{4}-5$ framework should be in tetrahedral coordination. The octahedrally coordinated $\mathrm{Fe}^{3+}$ observed before heating is attributed to the fact that water molecules are coordinated to $\mathrm{Fe}^{3+}$ centers through dative bonding. However, the water molecules are ready to be removed by heating or evacuation. Indeed, a FeAPO-5 sample after evacuation for $3 \mathrm{~h}$ gave the same XANES spectrum as that from heating.

Fig. 2 also shows the XANES of 1\% FeZSM-5 and $3 \%$ FeMCM-41 before and after heating at $200^{\circ} \mathrm{C}$ in $\mathrm{N}_{2}$. FeZSM-5 has a broader absorption edge and a strong pre-edge peak, while FeMCM-41 has a sharper edge peak and a weak pre-edge. Different from that observed on FeAPO-5, heating the samples does not change both of the spectra. The strong pre-edge confirms that $\mathrm{Fe}^{3+}$ in ZSM-5 is in tetrahedral coordination. In other words, $\mathrm{Fe}^{3+}$ should be incorporated in the framework of ZSM-5. In contrast, $\mathrm{Fe}^{3+}$ in MCM-41 was found to be in octahedral coordination and no transformation to tetrahedral was observed when the sample was heated at $200{ }^{\circ} \mathrm{C}$ in $\mathrm{N}_{2}$. This phenomenon is elucidated by the fact that the water molecules coordinated to the $\mathrm{Fe}^{3+}$ centers in MCM-41 are not as easily removed as that on $\mathrm{AlPO}_{4}-5$ framework.

The acidities of the Fe-substituted molecular sieves were examined by carrying out TPD of ammonia. Fig. 3 shows that $1 \%$ FeAPO-5 has a huge desorption peak that centered at ca. $150{ }^{\circ} \mathrm{C}$. The $1 \%$ FeZSM-5 has additional three peaks that appeared at 280, 430 and $540{ }^{\circ} \mathrm{C}$. On the other hand, $1 \%$ FeMCM-41 has a desorption peak at $515^{\circ} \mathrm{C}$ and $3 \%$ FeMCM-41 has a broad peak at $400{ }^{\circ} \mathrm{C}$. Considering that the $\mathrm{NH}_{3}$

Table 6

The composition and surface area of calcined FeZSM-5

\begin{tabular}{|c|c|c|c|c|c|c|c|}
\hline \multirow[t]{3}{*}{ Catalyst } & \multicolumn{6}{|c|}{ Molar ratio } & \multirow[t]{3}{*}{ BET surface area $\left(\mathrm{m}^{2} / \mathrm{g}\right)$} \\
\hline & \multicolumn{3}{|l|}{ Gel } & \multicolumn{3}{|c|}{ Product $^{\mathrm{a}}$} & \\
\hline & $\mathrm{Fe}$ & $\mathrm{Al}$ & $\mathrm{Si}$ & $\mathrm{Fe}$ & $\mathrm{Al}$ & $\mathrm{Si}$ & \\
\hline $1 \%$ AlZSM-5 & 0 & 0.01 & 1 & 0 & 0.028 & 1 & 370 \\
\hline $1 \%$ FeZSM-5 & 0.01 & 0 & 1 & 0.049 & 0 & 1 & 347 \\
\hline $2 \%$ FeZSM-5 & 0.02 & 0 & 1 & 0.051 & 0 & 1 & 300 \\
\hline
\end{tabular}

\footnotetext{
${ }^{\text {a }}$ Calcined samples.
} 

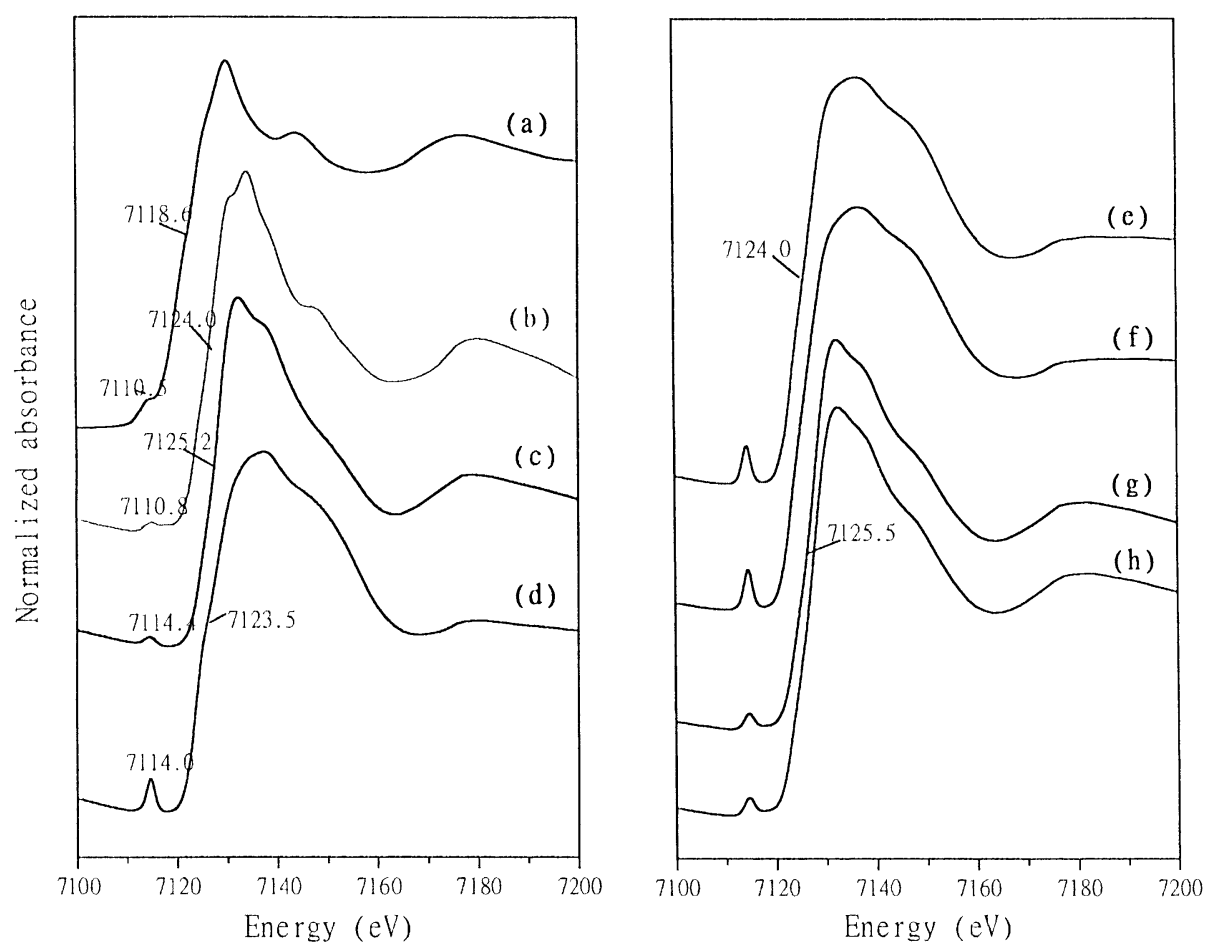

Fig. 2. XANES of FeK-edge: (a) FeO, (b) $\mathrm{Fe}_{2} \mathrm{O}_{3}$, (c) $1 \%$ FeAPO-5, (d) $1 \%$ FeAPO-5 dried at $200{ }^{\circ} \mathrm{C}$, (e) $1 \%$ FeZSM-5, (f) $1 \%$ FeZSM-5 dried at $200{ }^{\circ} \mathrm{C}$, (g) $1 \%$ FeMCM-41, and (h) $1 \%$ FeMCM-41 dried at $200^{\circ} \mathrm{C}$.

desorbed below $200{ }^{\circ} \mathrm{C}$ was due to physical adsorption, the acid amount was calculated based on the amount of $\mathrm{NH}_{3}$ desorbed in the range of $200-600^{\circ} \mathrm{C}$. For $1 \%$ FeAPO-5, 1\% FeZSM-5, 1\% FeMCM-41

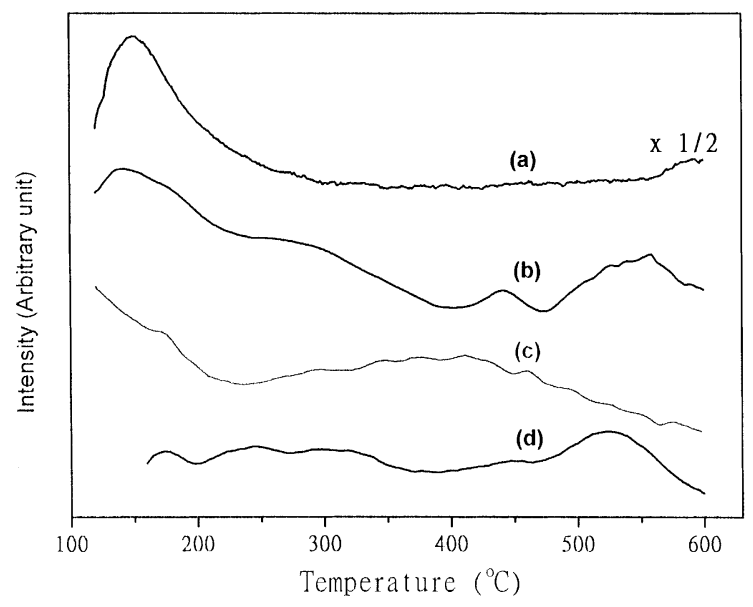

Fig. 3. $\mathrm{NH}_{3}$-TPD profiles of (a) $1 \%$ FeAPO-5, (b) $1 \%$ FeZSM-5, (c) $3 \%$ FeMCM-41, and (d) $1 \%$ FeMCM- 41. and $3 \%$ FeMCM-41, the values are $0.75,1.23,0.27$ and $0.60 \mathrm{wt} . \%$, or $0.97,1.26,0.10$ and $0.20 \mathrm{NH}_{3}$ molecule $/ \mathrm{nm}^{2}$ surface area, respectively. Although the value is relatively high for $1 \%$ FeAPO-5, the desorption occurs at relatively low temperature. These results demonstrate that $1 \%$ FeZSM-5 has the largest amount and strongest acidity among the four catalysts under investigation. In contrast, $1 \%$ FeAPO-5 has the weakest acidity.

\subsection{Catalytic activities}

Ten different vicinal diols were used as the reactants (Table 1). Compounds 1-3, 6 and 7 are 1,2-diols containing one primary alcohol and one secondary alcohol which has alkyl substitution of different chain length. The dielectric constant and hydrophilicity of these diol compounds decreases as the alkyl chain lengthens. Compound 4 contains two secondary alcohols, while compound 5 contains two tertiary alcohols. Compound 8 has one phenyl substitution, and compound 10 has two phenyl groups substituted on 
the two neighboring carbons of the diol. Compound 9 contains one tertiary alcohol and one secondary alcohol. It is the only cyclic molecule under investigation.

Our previous studies on pinacol rearrangement showed that the polarity of the solvent played an important role in affecting the pinacol conversion and pinacolone selectivity [8]. In the present studies, toluene was used as the exclusive solvent to examine other factors. The catalytic activities of Fe-substituted molecular sieves in pinacol-type rearrangement were found to be greatly influenced by the hydrophilicity and size of the diol compounds as well as their substitution.

Among the three Fe-substituted molecular sieves, FeAPO-5 was found to be the most efficient in catalyzing the pinacol rearrangement of 2,3-dimethyl-2,3butanediol (generally named pinacol), which has medium size among the diols (Table 7). Except the major product pinacolone, dimethylbutadiene (DMBDE) was the main side product (Scheme 1). Almost complete conversion of pinacol and $70 \%$ yield

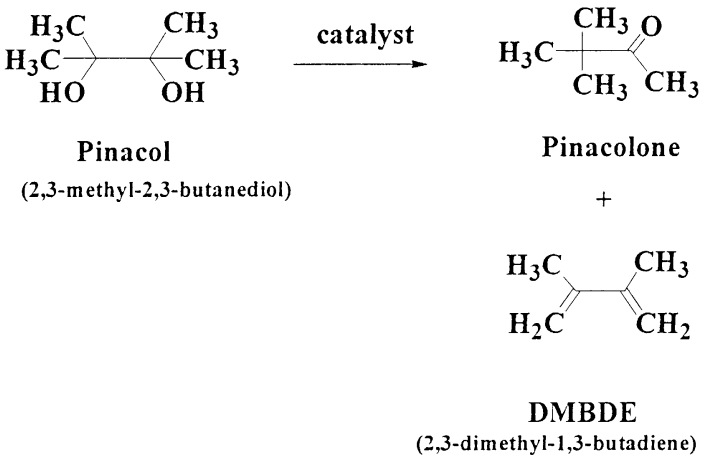

Scheme 1. Typical products obtained in pinacol rearrangement reaction.

of pinacolone were obtained over $\mathrm{AlPO}_{4}-5$-substituted with $0.5-2 \% \mathrm{Fe}$. When Fe-loading is higher than $2 \%$, pinacol conversion decreases. It was also found that pure $\mathrm{AlPO}_{4}-5$ or that impregnated with $\mathrm{Fe}\left(\mathrm{NO}_{3}\right)_{3}$ showed no catalytic activities. Therefore, $\mathrm{Fe}^{3+}$-substituted in the $\mathrm{AlPO}_{4}-5$ framework must be

Table 7

Pinacol rearrangement of 2,3-dimethy-2,3-butanediol over various Fe-molecular sieves ${ }^{\mathrm{a}}$

\begin{tabular}{|c|c|c|c|c|}
\hline \multirow[t]{2}{*}{ Catalyst } & \multirow[t]{2}{*}{ Pinacol conversion $(\%)$} & \multicolumn{2}{|l|}{ Yield $(\%)$} & \multirow[t]{2}{*}{ Pinacolone selectivity (\%) } \\
\hline & & Pinacolone & DMBDE & \\
\hline Blank & 0 & 0 & 0 & 0 \\
\hline Imp- $1 \%$ Fe $/ \mathrm{AlPO}_{4}-5$ & 0 & 0 & 0 & 0 \\
\hline $\mathrm{AlPO}_{4}-5$ & 0 & 0 & 0 & 0 \\
\hline $0.5 \%$ FeAPO-5 & 98 & 69 & 8.2 & 70 \\
\hline $1 \%$ FeAPO-5 & $\sim 100$ & 71 & 8.3 & 71 \\
\hline $2 \%$ FeAPO-5 & $\sim 100$ & 68 & 3.0 & 68 \\
\hline $3 \%$ FeAPO-5 & 60 & 43 & 4.0 & 72 \\
\hline $4 \%$ FeAPO-5 & 26 & 22 & 0.5 & 83 \\
\hline $1 \%$ AlZSM-5 & 0 & 0 & 0 & 0 \\
\hline $1 \%$ FeZSM-5 & 0 & 0 & 0 & 0 \\
\hline $2 \%$ FeZSM-5 & 0 & 0 & 0 & 0 \\
\hline MCM-41 & 13 & 1.7 & 0 & 14 \\
\hline $1 \%$ FeMCM-41 & 33 & 21 & 12 & 64 \\
\hline $2 \%$ FeMCM-41 & 30 & 20 & 6.0 & 67 \\
\hline 3\% FeMCM-41 & 35 & 9.0 & 2.0 & 26 \\
\hline 4\% FeMCM-41 & 16 & 13 & 2.0 & 81 \\
\hline R-0.5\% FeAPO-5 & 91 & 63 & 5.3 & 69 \\
\hline R-1\% FeAPO-5 & $\sim 100$ & 66 & 7.7 & 66 \\
\hline R-2\% FeAPO-5 & 94 & 63 & 1.8 & 67 \\
\hline
\end{tabular}

${ }^{\mathrm{a}}$ Conditions: weight ratio of pinacol:catalyst $=1: 1 ;$ solvent $=5 \mathrm{~g}$ toluene; $110^{\circ} \mathrm{C}, 6 \mathrm{~h} ; \mathrm{R}-0.5 \%$ FeAPO-5, R- $1 \%$ FeAPO-5, R-2\% FeAPO-5 $\Rightarrow$ regenerated catalysts. 
the catalytic active center. Moreover, $2 \%$ is probably the maximum loading that all $\mathrm{Fe}^{3+}$ ions can be incorporated in the $\mathrm{AlPO}_{4}-5$ framework. When the Fe-loading is higher than $2 \%$, a portion of $\mathrm{Fe}^{3+}$ probably forms iron oxide in the extra-framework, which is not catalytically active in pinacol rearrangement.

Table 7 also shows that the highest pinacol conversion and pinacolone yield over FeMCM-41 were ca. 30 and 20\%, respectively, while FeZSM-5 shows no catalytic activity at all. Since the results of ammonia TPD demonstrate that FeAPO-5 has the weakest acidity among the three Fe-incorporated molecular sieves, the catalytic activity toward pinacol rearrangement reaction over Fe-molecular sieves should not be due to the acidity. The null activity on FeZSM-5 is attributed to its pore diameter which is too small for pinacol to diffuse in freely. Based on the studies with X-ray absorption spectroscopy, the higher activity of FeAPO-5 in comparison to that of FeMCM-41 may be attributed to the more facile removal of coordinated water molecules from $\mathrm{Fe}^{3+}$ centers on $\mathrm{AlPO}_{4}-5$ than on MCM-41. As a result, the reactants can be adsorbed on the $\mathrm{Fe}^{3+}$ active centers more easily on FeAPO-5. In our previous studies, a reaction mechanism involving the redox of $\mathrm{Fe}^{3+}$ centers was proposed [8]. The mechanism is shown in Scheme 2. On the surface of the molecular sieve, the water molecule's dative bonding to the $\mathrm{Fe}^{3+}$ site is replaced by the pinacol molecule. The proton on the $\mathrm{OH}$ group which coordinates to $\mathrm{Fe}^{3+}$ becomes so acidic that it transfers easily to the vicinal $\mathrm{OH}$ group in pinacol molecule. The formation of $\mathrm{Fe}^{2+}-\mathrm{O}$ bond facilitates the dehydration of coordinated pinacol and stabilizes the carbenium ion intermediate. As the electron pair on the oxygen of $\mathrm{O}-\mathrm{Fe}^{2+}$ back-donates to the $\mathrm{C}-\mathrm{O}$ bond, the methyl group migrates to the cation site and $\mathrm{Fe}^{2+}$ is oxidized back to $\mathrm{Fe}^{3+}$. The pinacolone molecule formed is easily removed by the solvent and the coordination site around $\mathrm{Fe}^{3+}$ is replaced by another pinacol or water molecule.
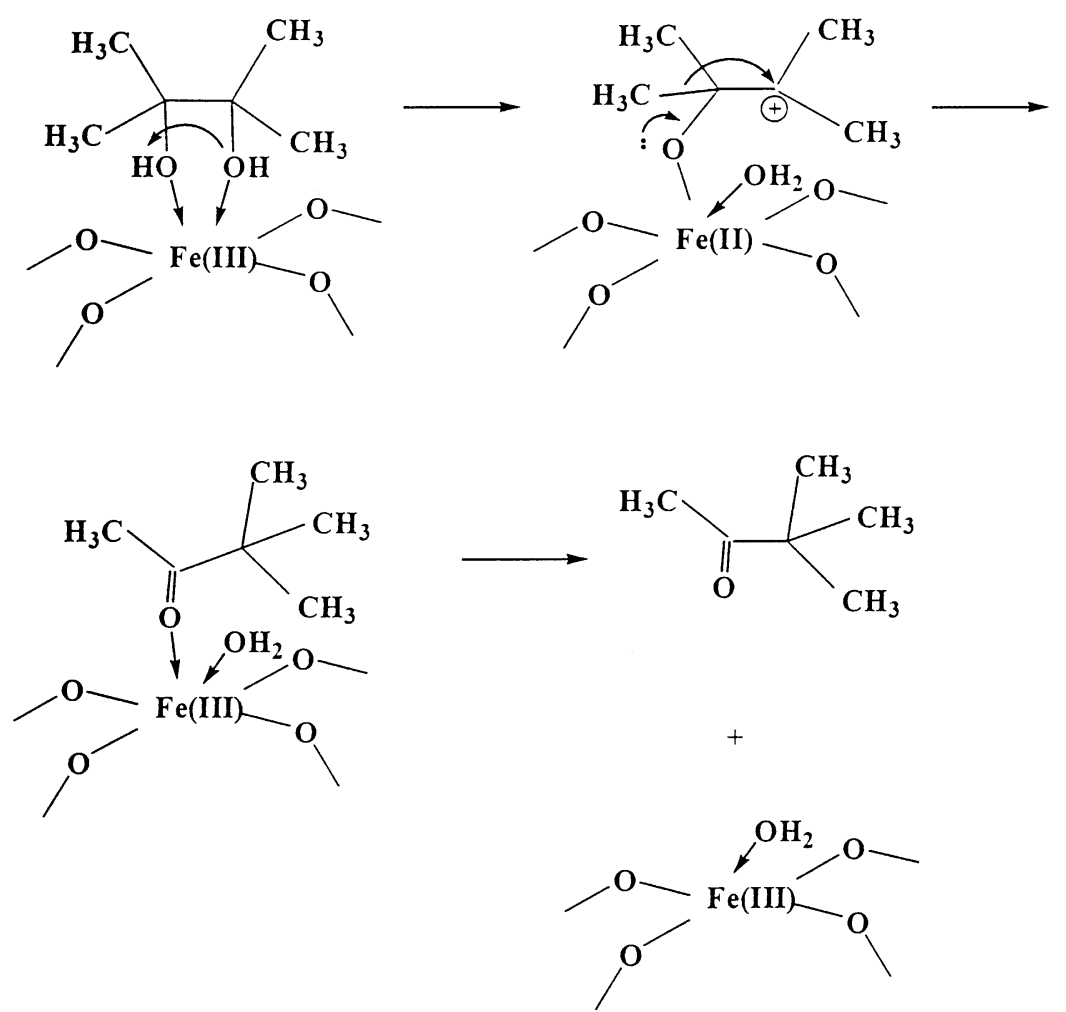

Scheme 2. Proposed reaction mechanism in pinacol rearrangement over $\mathrm{Fe}^{3+}$-substituted molecular sieves. 
For the purpose of examining any leaching of the metal ions into the solvent during the reaction, used FeAPO-5 catalysts were regenerated by separation from the reaction mixture and calcined at $560{ }^{\circ} \mathrm{C}$ for $6 \mathrm{~h}$ to burn off any surface coking species. Table 7 shows that the catalytic activities of the regenerated catalysts were close to that of the original catalysts. These results demonstrate that $\mathrm{Fe}^{3+}$-substituted in the $\mathrm{AlPO}_{4}-5$ framework is stable under the reaction condition and no leaching or deactivation of the catalysts was detected.

None of the three Fe-substituted molecular sieves was found to be catalytic active in the pinacol-type rearrangement of diol compounds $1-4,6$ and 7. These diol compounds are combinations of secondary and primary alcohols and they are more hydrophilic than 2,3-dimethyl-2,3-butanediol. Since the surfaces of $\mathrm{AlPO}_{4}-5$ and MCM-41 are also hydrophilic, it is suspected that these diol molecules may be adsorbed on the surfaces of FeAPO-5 and FeMCM-41 strongly and obstruct the rearrangement reaction to proceed. In contrast, the surface of ZSM-5 is relatively hydrophobic. However, FeZSM-5 also shows no catalytic activity. That is probably due to the fact that the hydrophobic surface of FeZSM-5 has low adsorption capability toward the hydrophilic diol molecules and the surface is probably covered by toluene solvent.

For compound 8, 1-phenyl-1,2-ethanediol, again none of the three Fe-molecular sieves contribute significant catalytic activities in the pinacol-type rearrangement. Table 8 shows that about 12 and 16\% conversions were observed in the blank and with plain $\mathrm{AlPO}_{4}-5$, respectively, while $21 \%$ was the highest conversion obtained over 4\% FeAPO-5. The low rearrangement activity of compound 8 over the molecular sieve catalysts is also attributed to its relatively high hydrophilicity. As to the small amounts of conversion observed in all reaction conditions, it is accounted for by that thermally stable benzylic cation is easily formed as the intermediate under the reaction condition.

FeMCM-41 was found to be very active in the pinacol-type rearrangement of large diol molecules such as 2,3-pinanediol and 1,2-diphenyl-1,2-ethanediol. Table 9 shows that the optimal activity in the rearrangement of 1,2-diphenyl-1,2-ethanediol was observed on MCM-41 incorporated with 3\% $\mathrm{Fe}^{3+}$, where as high as $84 \%$ conversion and $66 \%$ selectivity of 1,1-diphenylacetaldehyde were achieved. In this reaction, FeAPO-5 shows much

Table 8

Pinacol rearrangement of 1-phenyl-1,2-ethanediol over various Fe-molecular sieves ${ }^{\mathrm{a}}$

\begin{tabular}{|c|c|c|c|}
\hline \multirow[t]{2}{*}{ Catalyst } & \multirow{2}{*}{$\begin{array}{l}\text { 1-Phenyl-1, 2-ethanediol } \\
\text { conversion }(\%)\end{array}$} & \multicolumn{2}{|c|}{ Phenylacetaldehyde } \\
\hline & & Yield (\%) & Selectivity (\%) \\
\hline Blank & 12 & 8.4 & 72 \\
\hline Imp- $1 \% \mathrm{Fe} / \mathrm{AlPO}_{4}-5$ & 6.0 & 5.8 & 97 \\
\hline $\mathrm{AlPO}_{4}-5$ & 16.1 & 16 & $\sim 100$ \\
\hline $0.5 \%$ FeAPO- 5 & 17 & 17 & 98 \\
\hline $1 \%$ FeAPO-5 & 16 & 15 & 89 \\
\hline $2 \%$ FeAPO-5 & 19 & 19 & 98 \\
\hline $3 \%$ FeAPO-5 & 5.3 & 5.0 & 94 \\
\hline $4 \%$ FeAPO-5 & 21 & 21 & $\sim 100$ \\
\hline $1 \%$ AlZSM-5 & 15 & 15 & 98 \\
\hline $1 \%$ FeZSM-5 & 19 & 13 & 65 \\
\hline $2 \%$ FeZSM-5 & 13 & 12 & 92 \\
\hline MCM-41 & 9.0 & 8.8 & 98 \\
\hline $1 \%$ FeMCM-41 & 13 & 8.0 & 61 \\
\hline $2 \%$ FeMCM-41 & 14 & 8.5 & 63 \\
\hline $3 \%$ FeMCM-41 & 15 & 15 & $\sim 100$ \\
\hline $4 \%$ FeMCM-41 & 10 & 9.7 & 97 \\
\hline
\end{tabular}

${ }^{\text {a }}$ Conditions: weight ratio of reactant:catalyst $=1: 1$; solvent $=5 \mathrm{~g}$ toluene; $110^{\circ} \mathrm{C}, 6 \mathrm{~h}$. 
Table 9

Pinacol rearrangement of 1,2-diphenyl-1,2-ethandiol over various Fe-molecular sieves ${ }^{\mathrm{a}}$

\begin{tabular}{|c|c|c|c|c|c|}
\hline \multirow[t]{2}{*}{ Catalyst } & \multirow{2}{*}{$\frac{\left\langle\left.\left.\right|_{\mathrm{OH}} ^{*}\right|_{\mathrm{OH}} ^{\mathrm{H}}\right.}{\text { Conversion }(\%)}$} & \multicolumn{2}{|c|}{ ill } & \multicolumn{2}{|c|}{ 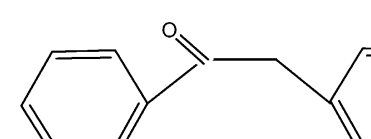 } \\
\hline & & Yield (\%) & Selectivity (\%) & Yield (\%) & Selectivity (\%) \\
\hline Blank & 14 & 5.0 & 36 & 8.8 & 63 \\
\hline Imp- $1 \% \mathrm{Fe} / \mathrm{AlPO}_{4}-5$ & 9.0 & 4.2 & 47 & 4.7 & 52 \\
\hline $\mathrm{AlPO}_{4}-5$ & 26 & 13 & 50 & 13 & 49 \\
\hline $0.5 \%$ FeAPO-5 & 33 & 22 & 67 & 11 & 33 \\
\hline $1 \%$ FeAPO-5 & 45 & 26 & 58 & 20 & 43 \\
\hline $2 \%$ FeAPO-5 & 36 & 16 & 47 & 19 & 54 \\
\hline $3 \%$ FeAPO-5 & 18 & 8.4 & 47 & 9.0 & 50 \\
\hline $4 \%$ FeAPO-5 & 20 & 11 & 53 & 9.0 & 45 \\
\hline $1 \%$ AlZSM-5 & 15 & 6.7 & 45 & 7.8 & 52 \\
\hline $1 \%$ FeZSM-5 & 18 & 6.8 & 38 & 11 & 61 \\
\hline $2 \%$ FeZSM-5 & 19 & 7.6 & 40 & 12 & 61 \\
\hline MCM-41 & 12 & 8.3 & 69 & 3.6 & 30 \\
\hline $1 \%$ FeMCM-41 & 58 & 44 & 76 & 13 & 23 \\
\hline $2 \%$ FeMCM-41 & 56 & 40 & 71 & 14 & 26 \\
\hline $3 \%$ FeMCM-41 & 84 & 55 & 66 & 29 & 34 \\
\hline $4 \%$ FeMCM-41 & 80 & 37 & 46 & 43 & 54 \\
\hline R-3\% FeMCM-41 & 86 & 62 & 72 & 24 & 28 \\
\hline R-4\% FeMCM-41 & 75 & 34 & 45 & 41 & 54 \\
\hline
\end{tabular}

\footnotetext{
${ }^{\mathrm{a}}$ Conditions: weight ratio of pinacol:catalyst $=1: 1$; solvent $=5 \mathrm{~g}$ toluene; $110{ }^{\circ} \mathrm{C}, 6 \mathrm{~h} ; \mathrm{R}-3 \%$ FeMCM- $41, \mathrm{R}-4 \% \mathrm{FeMCM}-41 \Rightarrow$ regenerated catalysts.
}

lower activity than FeMCM-41, while FeZSM-5 shows a low activity as that in the blank. Apparently, pore size is the main factor in determining the catalytic activity. However, the selectivities of the two main products, 1,1-diphenylacetaldehyde and benzylphenylketone varied with the catalysts. Over most of the FeMCM-41, the selectivities of 1,1-diphenylacetaldehyde were higher than those of benzylphenylketone. Over FeAPO-5, the selectivities of both products were almost equal. In contrast, in blank test and over FeZSM-5, the selectivities of benzylphenylketone were higher than those of 1,1-diphenylacetaldehyde. The formation of 1,1-diphenylacetaldehyde is through hydrogen migration and that of benzylphenylketone is through phenyl migration. In acid-catalyzed reaction, the migration of the phenyl group is usually favorable to that of hydrogen atom $[10,11]$. However, the phenyl group was also considered to have the ability to stabilize a neighboring cation center [11]. In this study, the large pore diameter of MCM-41 seems to have some contribution to the high selectivity of 1,1-diphenylacetaldehyde, which is bulkier than the other product. Table 9 also shows that the used FeMCM-41 catalysts after regeneration gave similar activities as the fresh catalysts, indicating the stability of the FeMCM-41 catalysts in the reaction.

In the pinacol-type rearrangement of cyclic diol, 2,3-pinanediol, the mesopores of FeMCM-41 show its advantage in the catalytic activity again (Table 10). The highest conversion was found over MCM-41 incorporated with $2-4 \% \mathrm{Fe}^{3+}$, and FeAPO-5 was the next active catalyst. It is also interesting to see that the selectivities of the products changed with different 
Table 10

Pinacol rearrangement of 2,3-pinanediol over various Fe-molecular sieves

\begin{tabular}{|c|c|c|c|c|c|}
\hline \multirow[t]{2}{*}{ Catalyst } & \multirow[b]{2}{*}{ Conversion (\%) } & \multicolumn{2}{|c|}{$\mathbf{I}$} & \multicolumn{2}{|c|}{ II } \\
\hline & & Yield (\%) & Selectivity (\%) & Yield (\%) & Yield (\%) \\
\hline $\mathrm{AlPO}_{4}-5$ & 0 & 0 & - & 0 & 0 \\
\hline $0.5 \%$ FeAPO-5 & 12.0 & 3.7 & 31 & 5.6 & 2.7 \\
\hline $1 \%$ FeAPO-5 & 18.0 & 4.5 & 25 & 9.2 & 4.5 \\
\hline $2 \%$ FeAPO-5 & 8.3 & 2.6 & 31 & 3.6 & 2.0 \\
\hline $3 \%$ FeAPO-5 & 8.4 & 1.5 & 18 & 4.7 & 2.2 \\
\hline $4 \%$ FeAPO-5 & 7.7 & 2.2 & 28 & 3.5 & 2.0 \\
\hline 1\% AlZSM-5 & 0 & 0 & - & 0 & 0 \\
\hline $1 \%$ FeZSM-5 & 7.1 & 1.2 & 17 & 3.1 & 2.8 \\
\hline $2 \%$ FeZSM-5 & 9.4 & 2.0 & 21 & 4.3 & 4.0 \\
\hline MCM-41 & 32 & 15 & 47 & 13 & 4.0 \\
\hline $1 \%$ FeMCM-41 & 75 & 31 & 41 & 34 & 10 \\
\hline $2 \%$ FeMCM-41 & 99 & 51 & 51 & 34 & 15 \\
\hline $3 \%$ FeMCM-41 & $\sim 100$ & 52 & 52 & 39 & 8.9 \\
\hline 4\% FeMCM-41 & $\sim 100$ & 54 & 54 & 35 & 11 \\
\hline
\end{tabular}

catalysts. Over FeMCM-41, the selectivities of product $\mathbf{I}$ are almost the same as those of the sum of other two products. However, over FeAPO-5 and FeZSM-5, the selectivities of products II and III are much higher than those of $\mathbf{I}$. The formation of product I is through hydrogen migration, while that of products II and III needs multiple steps of alkyl migration. In liquid acid-catalyzed reactions, hydrogen migration usually prefers to alkyl migration [10,11]. In other words, the selectivity of product I should be higher than that of products II and III. The discrepancy in product selectivity on Fe-substituted molecular sieves implies that the reaction mechanism is probably different. Besides, the surface of molecular sieves may stabilize carbenium intermediates of less steric hindrance, such as those lead to products II and III.

\section{Conclusions}

Ten vicinal diols were used as the reactants and three Fe-substituted molecular sieves of different pore sizes and structures were examined as catalysts in pinacol-type rearrangement. The diol compounds which have high conversions are those either with at least one tertiary alcohol or those with diphenyl substitution. The redox of the $\mathrm{Fe}^{3+}$ incorporated in the framework of molecular sieves was proposed to involve in the catalytic reaction. FeZSM-5 showed no significant catalytic activity in pinacol rearrangement of all 10 diol compounds, probably due to its small pore diameter and low adsorption capability toward the hydrophilic reactants. FeAPO-5 shows higher catalytic activity than FeMCM-41 in pinacol rearrangement of 2,3-dimethyl-2,3-butanediol because the more facile removal of coordinated water molecules from $\mathrm{Fe}^{3+}$ centers on $\mathrm{AlPO}_{4}-5$ than on MCM-41. On the other hand, Fe-substituted MCM-41 with relatively large pores was most active in catalyzing the rearrangement of large molecules such as 2,3-pinanediol and 2,3-diphenyl-1,2-ethanediol. In other words, pore size is also an important factor in determining the catalytic activity. The product selectivities over Fe-substituted molecular sieves were different from that obtained using liquid acids as the catalyst. The intermediate of less 
steric hindrance which is more easily stabilized on the solid surface probably determines the product selectivity.

\section{Acknowledgements}

Financial support from National Science Council, Taiwan is gratefully acknowledged. The authors also extend our acknowledgment to CONDEA Vista for a free sample of pseudo-boehmite.

\section{References}

[1] T. Blasco, M.A. Camblor, A. Corma, J. Pérez-Parienté, J. Am. Chem. Soc. 115 (1993) 11806.
[2] J.S. Reddy, P.A. Jacobs, J. Chem. Soc., Perkin Trans. I 22 (1993) 2665.

[3] C.A. Buehler, D.E. Pearson, Survey of Organic Synthesis, Wiley/Interscience, New York, 1970, p. 677.

[4] P. de Mayo, Rearrangement in Ground and Excited States, Vol. 1, Academic Press, New York, 1985.

[5] C.P. Bezouhanoova, F.A. Jabur, J. Mol. Catal. 87 (1994) 39.

[6] F.A. Jabur, V.J. Penchev, C.P. Bezoukhanova, J. Chem. Soc., Chem. Commun. (1994) 1591.

[7] Y. Toyoshi, T. Nakato, T. Okuhara, Bull. Chem. Soc. Jpn. 71 (1998) 2817.

[8] B.-Y. Hsu, S. Cheng, Microporous Mesoporous Mater. 21 (1998) 505.

[9] B. Douglas, D. McDaniel, J. Alexander, Concepts and Models of Inorganic Chemistry, 3rd Edition, Wiley, New York, 1994, pp. 225-226.

[10] K. Nakamura, Y. Osamura, Tetrahedron Lett. 31 (1990) 251.

[11] K. Nakamura, Y. Osamura, J. Am. Chem. Soc. 115 (1993) 9112. 